\title{
Investigations on the methane adsorption behaviors of ultrasonic bath assisted bituminous coal
}

\author{
Yanyan Feng, Wen Yang, Chengfa Jiang, Wei Chu* \\ Department of Chemical Engineering, Sichuan University, Chengdu 610065, China
}

Email address:

feng19880213@163.com (Yanyan Feng), chuwei1965scu@163.com (Wei Chu)

\section{To cite this article:}

Yanyan Feng, Wen Yang, Chengfa Jiang, Wei Chu. Investigations on the Methane Adsorption Behaviors of Ultrasonic Bath Assisted Bituminous Coal. International Journal of Oil, Gas and Coal Engineering. Vol. 1, No. 2, 2013, pp. 23-28.

doi: $10.11648 /$ j.ogce.20130102.12

\begin{abstract}
The purpose of this work was to prepare coals with various pore structures, and investigate both microporosity development and corresponding methane adsorption capacities. A series of coal samples have been prepared by ultrasonic bath, and characterized by $\mathrm{N}_{2}$ adsorption and scanning electron microscopy (SEM) to obtain the pore structure and surface morphology of the samples. Methane adsorption measurement was conducted in the temperature range $25 \sim 55{ }^{\circ} \mathrm{C}$ and at pressures of up to $3.5 \mathrm{MPa}$. The Langmuir equation was applied to fit the experimental data, and the result showed the methane uptake correlated to the micropore volume and surface area, provided by the adsorption of $\mathrm{N}_{2}$ at $77 \mathrm{~K}$. The surface area, pore volume, pore size distribution and surface morphology of the coal have changed significantly when treated for 10 min, resulting in the maximum of methane adsorption capacity. With the time further increasing, the surface area, pore volume and microporosity of the coal samples were reduced, along with the decrease of methane adsorption capacity. It can be concluded that the surface area, pore volume and microporosity had positive correlations with the amount of methane adsorption. The attenuation coefficient of the saturated adsorption amount over the coal samples substantially presented an inverse 'U-shape', indicating that the variation of the saturated adsorption amount was mainly controlled by the pore structure. Moreover, the temperature had a certain relationship with the attenuation coefficient of the saturated adsorption amount.
\end{abstract}

Keywords: Methane, Ultrasonic Treatment, Coal, Adsorption, Temperature

\section{Introduction}

Coalbed methane (CBM) exploration and development have increased people's attention due to their important strategic significances for the adjustment of energy structure, environmental protection and coal mine safety [1-4]. CBM, whose main component is methane, produced in the pore surfaces of coal matrix in the coal-forming process $[5,6]$. Safety issues associated with the mining of gassy coal seams have prompted studies of methane $\left(\mathrm{CH}_{4}\right)$ adsorption of coal [7]. Further development is clearly required to improve the technology while decreasing the risks and hazards of CBM exploitation in unmineable coal seams [8]. The main factors affecting methane adsorption behavior are coal metamorphism $[9,10]$, macerals $[11,12]$, pore structure [13-16], temperature [17], pressure [18-21], etc [22-24].

Changes of reservoir properties have a direct relationship with gas content in coal seam. Even with the similar burial depths and metamorphism of the coals, the pore structure may vary with the different geological processes due to the coal anisotropy [25]. Pore structure has a huge impact on gas content. According to the literature, pores of coal can be divided into macropores (diameter $>100 \mathrm{~nm}$ ), mesopores (diameter 100 10 nm) and micropores (pore size $<10 \mathrm{~nm}$ ) [14]. It has been reported that the micropores positively correlated to methane adsorption capacity, and the more microporous, the greater the amount of methane adsorption [2]. Herein, methane adsorption capacity is not only affected by the pore structure of coal (pore size distribution), but also the micropore volume and surface area [13]. But there were little literature for investigating the effects of the surface area and micropore volume. Therefore, it is necessary to further study the pore structure on methane adsorption.

It has become desirable to understand the seismic/sonic response of $\mathrm{CBM}$ on the coal as a function of water injection, especially in the context of restructuring the 
world's economy for a low-emissions future [26]. Up to now, it was rarely reported the effects of ultrasonic treatment [26] on the pore structure of the coal. In this paper, we examined the ultrasonic treatment on the pore structure in detail and the corresponding changes in the methane adsorption properties of coals. To quantify the relationship between the adsorption temperature and the saturated adsorption capacity, since the temperature increased $1{ }^{\circ} \mathrm{C}$, the saturated adsorption capacity reduced was defined as the attenuation coefficient of saturated adsorption capacity $\left(\alpha, \mathrm{mmol} /\left(\mathrm{g} \cdot{ }^{\circ} \mathrm{C}\right)\right)$.

\section{Experimental}

\subsection{Sample Preparation}

The bituminous coal, collected from Datong coalfield in Shanxi province (China), was selected as the sample. The coal sample was crushed to particles with size fraction of 40-60 mesh, subsequently dried in an oven overnight at 383 $\mathrm{K}$ and stored in a sealed plastic container [1]. Proximate analysis for the coal was given in Table 1 .

Table 1. The proximate analysis of the sample (air-dried basis, wt \%)

\begin{tabular}{cccc}
\hline Fixed carbon & Volatile matter & Moisture & Ash \\
\hline 66.23 & 9.68 & 0.41 & 23.68 \\
\hline
\end{tabular}

It was further divided into five portions. The first portion was nominated as DT0 with no treatment, and the others were respectively named as DT10, DT30, DT60, DT120 with different times 10, 30, 60, 120 min under ultrasonic bath at $25{ }^{\circ} \mathrm{C}$. Then the materials were washed with distilled $\mathrm{H}_{2} \mathrm{O}$, followed by drying at $110{ }^{\circ} \mathrm{C}$ for $24 \mathrm{~h}$, and stored in a sealed plastic container.

\subsection{Characterization}

The textural characterization of coals was based on $\mathrm{N}_{2}$ adsorption/desorption isotherms, determined at $77 \mathrm{~K}$ with a NOVA1000e surface area and pore size analyzer (Quantachrome Company). Samples were degassed at 383 $\mathrm{K}$ for $24 \mathrm{~h}$ prior to the analysis [1]. The surface area was calculated by the BET method; the micropore $(<10 \mathrm{~nm})$ volume, mean pore diameter and the pore size distribution were determined by BJH equation.

Surface morphology was investigated by scanning electron microscopy (SEM) (JEOL/EO JSM-5900 microscope).

\subsection{Methane Adsorption}

Methane adsorption measurements were conducted by a volumetric method, and the schematic arrangement was similar to that previously described $[1,2]$. Before the measurement, the coal was dried at $383 \mathrm{~K}$ in a vacuum oven for at least $12 \mathrm{~h}$; followed $5 \mathrm{~g}$ of the sample was immediately placed into the adsorption cell, and degassed for about $3 \mathrm{~h}$. As He cannot be adsorbed at pressures below $10 \mathrm{MPa}$, it was used for the calibration of the void volume in the adsorption setup. The purities of $\mathrm{He}$ and methane were $99.999 \%$ and $99.99 \%$, respectively. The methane adsorption measurement was similar to that of helium calibration, and the measurements were operated at pressures up to $3.5 \mathrm{MPa}$ in the temperature range $25 \sim 55^{\circ} \mathrm{C}$. To ensure the accuracy of the experimental data, the test was repeated three times and the mean value of the equilibrium data was used to calculate the adsorption isotherm [1].

\section{Results and Discussion}

\subsection{Textural Characterization}

Based on the knowledge of the nature of coal and its pore system, $\mathrm{N}_{2}$ adsorption/desorption, combined with SEM, could characterize the pore structure. Table 2 summarized the textural parameters for the coal samples. The pore size distributions were presented in Fig. 1.

Table 2. Physical properties of the coal samples

\begin{tabular}{cccc}
\hline Sample & $\begin{array}{c}\text { Surface } \\
\text { area, } \\
\text { BET }\left(\mathbf{~}^{2} / \mathbf{g}\right)\end{array}$ & $\begin{array}{c}\text { Pore volume, BJH } \\
\left(\times \mathbf{1 0}^{-3} \mathbf{~ c m}^{\mathbf{3}} / \mathbf{g}\right)\end{array}$ & $\begin{array}{c}\text { Mean pore diameter } \\
(\mathbf{n m})\end{array}$ \\
\hline DT0 & 1.331 & 3.475 & 2.078 \\
DT10 & 4.383 & 6.416 & 2.214 \\
DT30 & 2.438 & 3.933 & 2.223 \\
DT60 & 2.133 & 3.713 & 2.224 \\
DT120 & 0.784 & 2.362 & 2.073 \\
\hline
\end{tabular}

The BET surface area, and micropore volume were apt to be increased with ultrasonic processing for $10 \mathrm{~min}$. Compared with DT0, the surface area of the sample DT10 increased 2.29 times from $1.331 \mathrm{~m}^{2} / \mathrm{g}$ to $4.383 \mathrm{~m}^{2} / \mathrm{g}$, while the micropore volume increased by $84.63 \%$. With the increase of processing time, the microporosity of the samples decreased. When processing for $120 \mathrm{~min}$, the surface area and micropore volume of the sample DT120 were even smaller than DT0, with the surface area decreasing by $41.10 \%$, and the micropore volume reduced from $3.475 \times 10^{-3} \mathrm{~cm}^{3} / \mathrm{g}$ to $2.362 \times 10^{-3} \mathrm{~cm}^{3} / \mathrm{g}$. It revealed that the ultrasonic treatment could alter the pore structures of coals, and the changes of the pore structures were related to the processing time. When handling with $10 \mathrm{~min}$, the ash previously blocked at aperture (carbonates, sulfates, silicates and other minerals) was removed, and the pores became more developed. As the processing time increasing, the pore structure of the samples was aggravatingly damaged with the collapse of pore walls. The longer the processing time, the more serious the collapse was.

As shown in Fig. 1, the micropores changed obviously by ultrasonic processing, and the pore size distributions of coals were also greatly influenced by the processing time. 
When the processing time increased to $10 \mathrm{~min}$, the pores moved towards the micropores, and there existed a significant quantity of pores in the microporous region, with the average pore diameter estimated to be $2.214 \mathrm{~nm}$; with the time further increasing from $10 \mathrm{~min}$ to $60 \mathrm{~min}$, the micropore contents of coals were reduced, but greater than DT0; when increased to $120 \mathrm{~min}$, the micropores decreased sharply, and less than the sample DT0. The variation in the textural characteristics was due to the process of ultrasonic treatment, which accounted for both creation of micropores and damage of the pore walls of the coal.

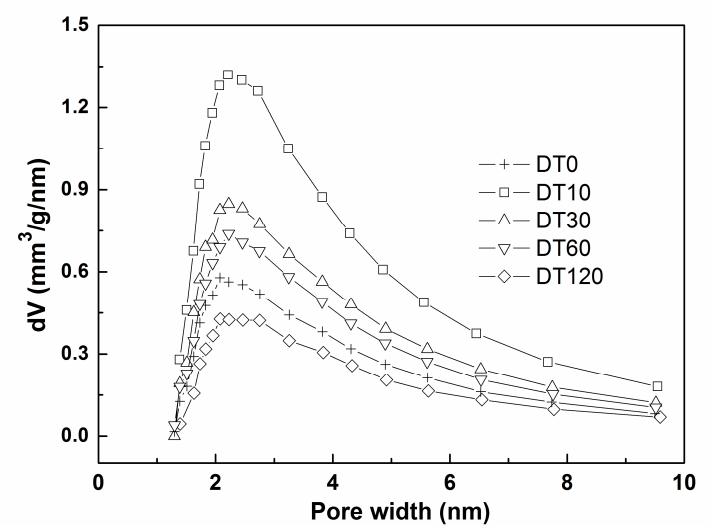

Figure 1. Pore size distributions obtained by applying the BJH equation.
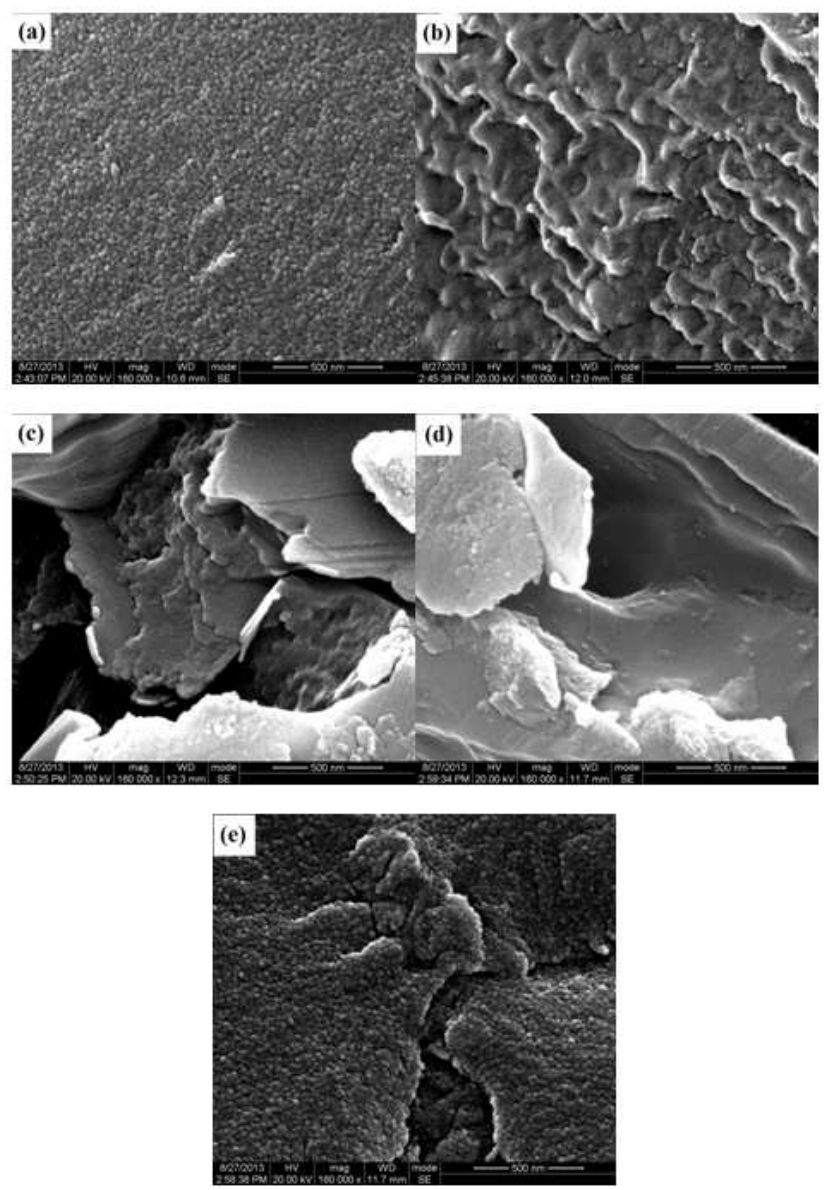

Figure 2. SEM images of the samples DT0 (a), DT10 (b), DT30 (c), DT60 (d) and DT120 (e).
Scanning electron micrographs of samples were shown in Fig. 2. The examination of the structure of samples showed the presence of micropores and geometries at the surface. Fig. 2(a) displayed the SEM micrograph of the coal obtained without any treatment, and the surface of the sample was smooth. The SEM micrographs of Fig. 2(b), (c) and (d) showed that compared with DT0, the increment of processing time from $10 \mathrm{~min}$ to $60 \mathrm{~min}$ had increased the porosity of the surface. In Fig. 2(b), the sample DT10 had a pocket-like morphology with wrinkled paper structure, and a significant microporous texture in which pore sizes were about a few $\mathrm{nm}$ in diameter, consistent with possessing the largest surface area and pore volume. Compared with DT10, the surfaces of DT30 and DT60 were damaged more seriously with disordered, bent, or small pieces.

\subsection{Methane Adsorption Isotherms}

Since the Langmuir model has only two parameters and been widely used in the field of CBM [1, 22, 23, 27], it was applied to fit the adsorption data in this work. Fig. 3 showed methane adsorption isotherms of the five samples at $298 \mathrm{~K}$ and pressures up to $3.5 \mathrm{MPa}$, and the solid lines were with the isotherms adhering to Langmuir model. It can be seen that the Langmuir model fitted the data well, and the Langmuir parameters were described in Table 3. The methane adsorption isotherms were Type I of IUPAC. Among the samples, the sample DT10 possessed the highest methane adsorption capacity and the DT120 sample possessed the least methane adsorption capacity. The adsorption capacity decreased as the BET surface area and pore volume of the samples decreased.

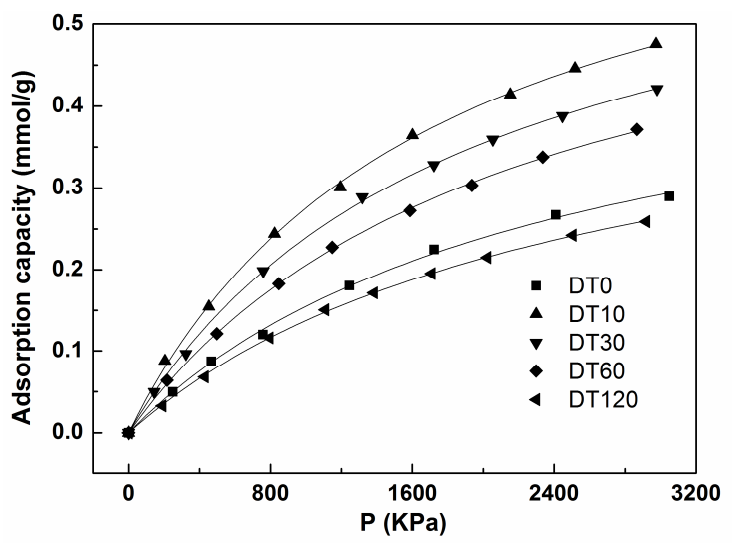

Figure 3. Methane adsorption isotherms obtained by applying the

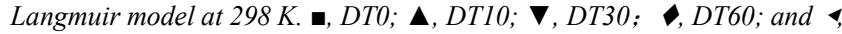
DT120; solid line, fitted by the Langmuir model.

Table 3. Langmuir parameters of equilibrium isotherms at $298 \mathrm{~K}$

\begin{tabular}{ccc}
\hline Sample & $\boldsymbol{n}_{\mathbf{0}}(\mathbf{m m o l} / \mathbf{g})$ & $\mathbf{b}\left(\mathbf{M P a}^{-1}\right)$ \\
\hline DT0 & 0.527 & 0.42 \\
DT10 & 0.748 & 0.58 \\
DT30 & 0.685 & 0.54 \\
DT60 & 0.644 & 0.47 \\
DT120 & 0.485 & 0.40 \\
\hline
\end{tabular}


As shown in Fig. 3, methane adsorption capacities of the samples were in an ascending order of DT120<DT0 < DT60 $<$ DT30 $<$ DT10, and the highest methane adsorption capacity corresponded to the sample with the highest micropore volume and surface area. The trend of the adsorption isotherms of the samples had not changed: the adsorption amount within the range of low pressures increased faster than in the high pressures, and with the increase of the pressure, the adsorption amount had changed little in the high pressure range. But methane adsorption capacities of the samples treated by various processing times have undertaken different changes. The sample DT10 possessing the highest methane adsorption was attributed to the orderly arranged surface, large surface area and appropriate pore size distribution, all conducive to methane adsorption. Since adsorption mainly occurred in micropores, the microporosity of samples DT30 and DT60 with ultrasonic processing was less than DT10 but larger than DT0, thus their methane adsorption capacities fell in between samples DT10 and DT0. The methane adsorption capacity of DT120 was lower than DT0 due to the less micropores. It revealed that the ultrasonic treatment has an important effect on methane adsorption behavior. Methane adsorption capacities have changed along with change of micropore size distributions of coals, and the adsorption capacity was positively correlated to the micropore size distribution. The result showed that the development of microporosity was bound to increase the surface area and micropore volume, thus providing more space for methane adsorption.
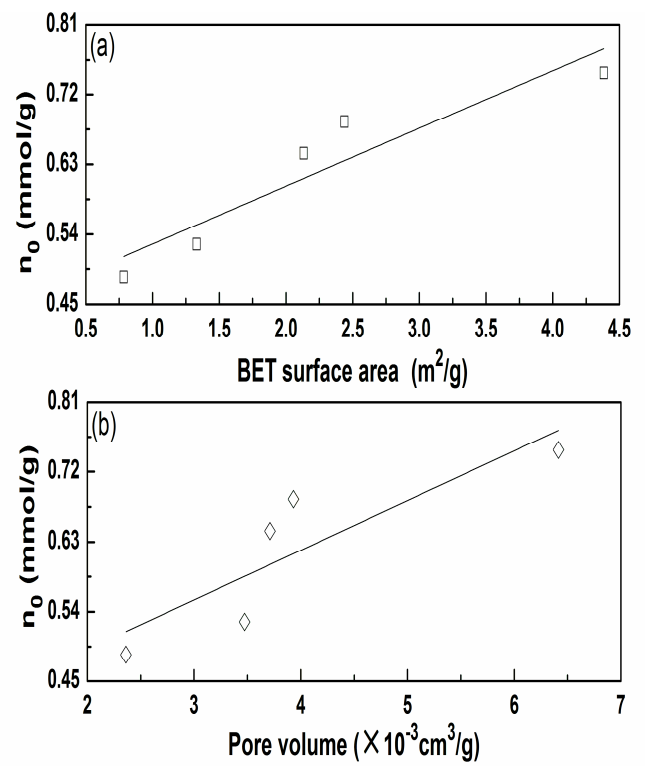

Figure 4. Relationship between the saturated adsorption amount and the surface area (a), pore volume (b).

The relationship between $n_{0}$ and BET surface area was presented in Fig. 4(a). As a general trend, $n_{0}$ is roughly proportional to the BET surface area of the samples and the correlation coefficient $\mathrm{R}^{2}$ was 0.836 . The relationship between $n_{0}$ and BJH pore volume was displayed in Fig. 4(b) and the correlation coefficient $\mathrm{R}^{2}$ was 0.674 . The correlation coefficient between $n_{0}$ and BET surface area was higher than that for $\mathrm{BJH}$ pore volume, indicating the surface area was a more advantageous factor than pore volume on methane adsorption on coals.

In order to investigate the relationship between the temperature and the saturated adsorption amount, methane adsorption measurements were conducted at 25, 40 and $55^{\circ} \mathrm{C}$, respectively. Fig. 5 showed methane adsorption isotherms of coal samples at different temperatures, and the solid lines were from the Langmuir equation.
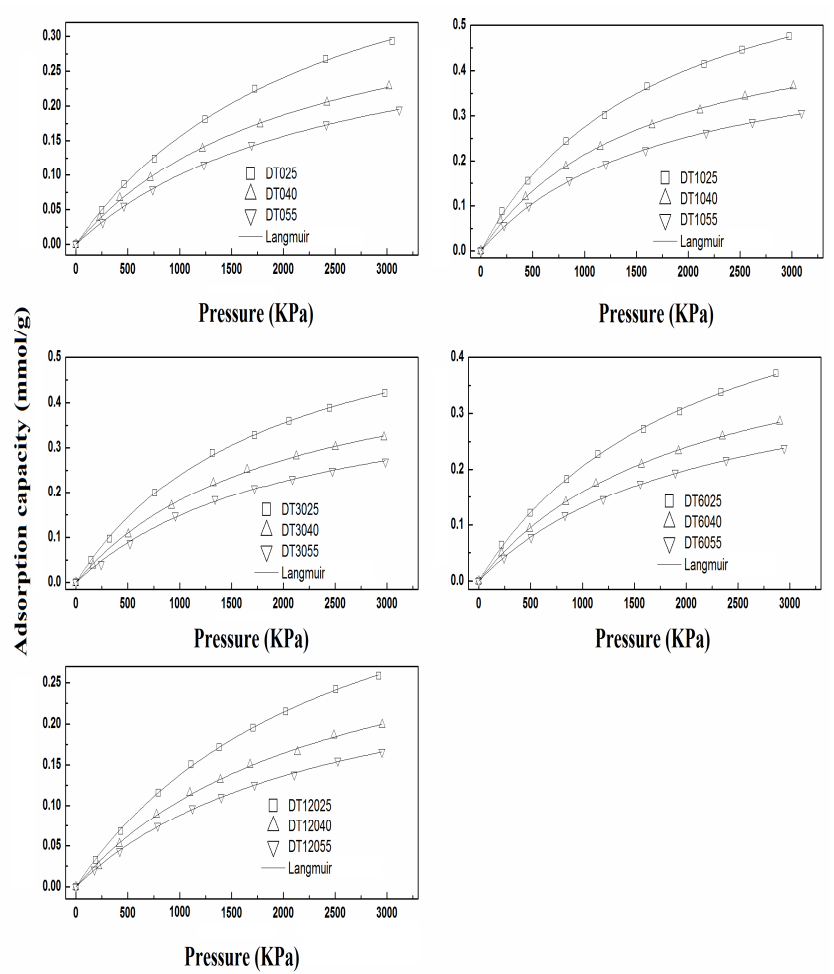

Figure 5. Equilibrium isotherms obtained by applying Langmuir model at different temperatures.

The increasing temperature promoted the methane desorption, and the higher the pressure, the more obvious the trend. Although temperature is advantageous to the internal diffusion of methane in coal bed, due to the exothermic process for adsorption, the increase of temperature eventually resulted in the decrease of methane adsorption capacity of coal samples.

To quantify the relationship between the adsorption temperature and the saturated adsorption capacity, since the temperature increased $1{ }^{\circ} \mathrm{C}$, the saturated adsorption capacity reduced was defined as the attenuation coefficient of saturated adsorption capacity $\left(\alpha, \mathrm{mmol} /\left(\mathrm{g} \cdot{ }^{\circ} \mathrm{C}\right)\right)$. In the range of $25 \sim 40{ }^{\circ} \mathrm{C}$, the attenuation coefficient of saturated adsorption capacity, $\alpha$, was $0.008 \sim 0.013 \mathrm{mmol} /$ $\left(\mathrm{g} \cdot{ }^{\circ} \mathrm{C}\right)$, with an average of $0.010 \mathrm{mmol} /\left(\mathrm{g} \cdot{ }^{\circ} \mathrm{C}\right)$; at $40 \sim 55^{\circ}$ $\mathrm{C}$, $\alpha$ was $0.0026 \sim 0.008 \mathrm{mmol} /\left(\mathrm{g} \cdot{ }^{\circ} \mathrm{C}\right)$, with an average of $0.0049 \mathrm{mmol} /\left(\mathrm{g} \cdot{ }^{\circ} \mathrm{C}\right)$. That is, as the temperature increased by $15{ }^{\circ} \mathrm{C}$, the decreasing rate of adsorption capacity was reduced by half. Furthermore, the value of $\alpha$ differed with 
the varied pore structures. With the increase of processing time, $\alpha$ substantially presented an inverse 'U-shape' (shown in Fig. 6), suggesting that changes in adsorption capacities were largely controlled by the pore structures of coal samples. The value of $\alpha$ was the maximum for the coal sample dealing with $10 \mathrm{~min}$, due to the highest surface area, micropore volume and micropores. When treated for 30, 60, $120 \mathrm{~min}$, little difference of $\alpha$ existed in the range of $25 \sim$ $40{ }^{\circ} \mathrm{C}$ and $40 \sim 55{ }^{\circ} \mathrm{C}$, indicating the influence of temperature on the adsorption capacity had decreased.

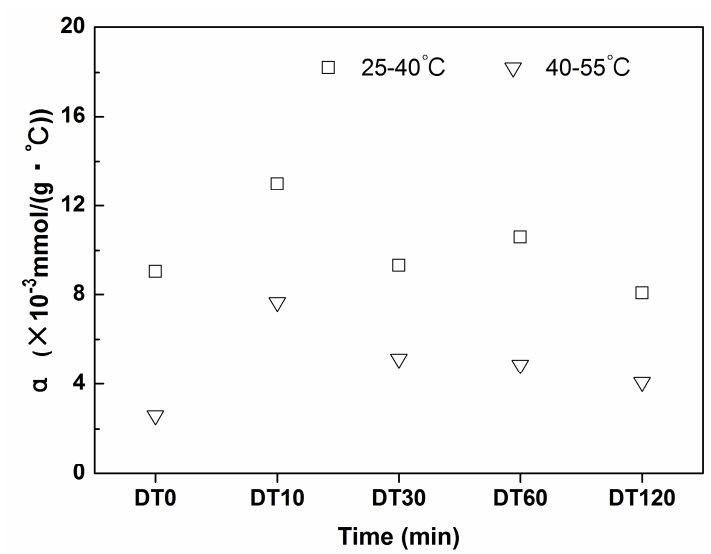

Figure 6. Relationship between the attenuation coefficient of saturated adsorption amount, temperature and processing time.

\section{Conclusion}

Methane adsorption behaviors of the treated coals were studied in this work. The result showed that the pore structure of coal sample have changed with ultrasonic treatment. The adsorption characteristics of methane onto coals were performed at $25 \sim 55{ }^{\circ} \mathrm{C}$ and pressures up to 3.5 MPa by a volumetric method. The experimental data were fitted to the Langmuir model, and according to the goodness-of-fit, the Langmuir model was in good agreement with experimental data. The methane adsorption over the coals involved in their physical structures. Main factors, such as surface area, pore size distribution, and micropore volume, could affect the adsorption of methane on coals. The greater the surface area and micropore volume, the higher the adsorption capacity. The attenuation coefficient of the saturated adsorption amount of coal samples displayed an inverse 'U-shape', and was controlled by the pore structure, as well as the temperature.

Herein, it could be considered to inject $\mathrm{H}_{2} \mathrm{O}$ into coal seam combined with the mechanical force to improve CBM exploration. Coal, with CBM retained in the coal seam, is a porous material. When $\mathrm{H}_{2} \mathrm{O}$ was injected into the coal seam, the effect of mechanochemistry should be considered, as well as the mode and the duration of the mechanical force. Different durations could lead to various adsorption/desorption behaviors, and the appropriate duration was in favor of CBM exploration and development.

\section{Acknowledgments}

This work was supported by the National Basic Research Program of China (973 Program, No. 2011CB201202). The authors also thank Yanjun Li for the samples preparation.

\section{References}

[1] Y. Y. Feng, W. Yang, D. J. Liu, and W. Chu, "Surface modification of bituminous coal and its effects on methane adsorption," Chinese J. Chem. 2013, 31(8): 1102-1108.

[2] J. J. Luo, Y. F. Liu, C. F. Jiang, W. Chu, W. Jie, and H. P. Xie, "Experimental and modeling study of methane adsorption on activated carbon derived from anthracite," J. Chem. Eng. Data 2011, 56(12): 4919-4926.

[3] R. Pini, D. Marx, L. Burlini, G. Storti, and M. Mazzotti, "Coal characterization for ECBM recovery: gas sorption under dry and humid conditions, and its effect on displacement dynamics," 10th International Conference on Greenhouse Gas Control Technologies 2011, 4: 2157-2161.

[4] E. C. Gaucher, P. D. C. Defossez, M. Bizi, D. Bonijoly, J. R. Disnar, F. Laggoun-Defarge, C. Garnier, G. Finqueneisel, T. Zimny, and D. Grgic, "Coal laboratory cha racterisation for $\mathrm{CO}_{2}$ geological storage," 10th International Conference on Greenhouse Gas Control Technologies 2011, 4: 3147-3154.

[5] Y. Zhao, H. Y. Peng, "Study on the coupling characteristics of coal matrix, fracture and CBM under vibration," Disa. Adv. 2013, 6: 291-297.

[6] X. Y. Lin, X. B. Su, and J. H. Zeng, "Recoverable potential of coalbed methane in the Wangying-Liujia depression, Fuxin basin, China," Energ. Explor. Exploit. 2012, 30(3): 477-498.

[7] E. Ozdemir, K. Schroeder, "Effect of moisture on adsorption isotherms and adsorption capacities of $\mathrm{CO}_{2}$ on coals," Energ. Fuel 2009, 23: 2821-2831.

[8] C. M. White, D. H. Smith, K. L. Jones, A. L. Goodman, S. A. Jikich, R. B. Lacount, S. B. Dubose, E. Ozdemir, B. I. Morsi, and K. T. Schroeder, "Sequestration of carbon dioxide in coal with enhanced coalbed methane recovery-A review," Energ. Fuel 2005, 19(3): 659-724.

[9] D. F. Zhang, Y. J. Cui, B. Liu, S. G. Li, W. L. Song, and W. G. Lin, "Supercritical pure methane and $\mathrm{CO}_{2}$ adsorption on various rank coals of China: Experiments and Modeling," Energ. Fuel 2011, 25(4): 1891-1899.

[10] C. Garnier, G. Finqueneisel, T. Zimny, Z. Pokryszka, S. Lafortune, P. D. C. Defossez, and E. C. Gaucher, "Selection of coals of different maturities for $\mathrm{CO}_{2}$ Storage by modelling of $\mathrm{CH}_{4}$ and $\mathrm{CO}_{2}$ adsorption isotherms," Int. J. Coal Geol. 2011, 87(2): 80-86.

[11] Y. M. Lv, D. Z. Tang, H. Xu, and H. H. Luo, "Production characteristics and the key factors in high-rank coalbed methane fields: A case study on the Fanzhuang Block, Southern Qinshui Basin, China," Int. J. Coal Geol. 2012, 96-97: 93-108.

[12] S. D. Golding, I. T. Uysal, C. J. Boreham, D. Kirste, K. A. Baublys, and J. S. Esterle, "Adsorption and mineral trapping dominate $\mathrm{CO}_{2}$ storage in coal systems," 10th International Conference on Greenhouse Gas Control Technologies 2011, 


\section{4: 3131-3138.}

[13] Y. B. Melnichenko, L. L. He, R. Sakurovs, A. L. Kholodenko, T. Blach, M. Mastalerz, A. P. Radlinski, G. Cheng, and D. F. R. Mildner, "Accessibility of pores in coal to methane and carbon dioxide," Fuel 2012, 91(1): 200-208.

[14] Y. Yao, D. Liu, D. Tang, S. Tang, and W. Huang, "Fractal characterization of adsorption-pores of coals from North China: An investigation on $\mathrm{CH}_{4}$ adsorption capacity of coals," Int. J. Coal Geol. 2008, 73(1): 27-42.

[15] S. Zhang, S. Yang, J. Cheng, B. Zhang, and C. Lu, "Study on relationships between coal fractal characteristics and coal and gas outburst," Procedia Engineer 2011, 26.

[16] L. L. He, Y. B. Melnichenko, M. Mastalerz, R. Sakurovs, A. P. Radlinski, and T. Blach, "Pore accessibility by methane and carbon dioxide in coal as determined by neutron scattering," Energ. Fuel 2012, 26(3): 1975-1983.

[17] R. Sakurovs, S. Day, S. Weir, and G. Duffy, "Temperature dependence of sorption of gases by coals and charcoals," Int. J. Coal Geol. 2008, 73(3-4): 250-258.

[18] A. Mouahid, D. Bessieres, F. Plantier, and G. Pijaudier-Cabot, "A thermostated coupled apparatus for the simultaneous determination of adsorption isotherms and differential enthalpies of adsorption at high pressure and high temperature," J. Therm. Anal. Calorim. 2012, 109(2): 1077-1087.

[19] S. A. Mohammad, K. A. M. Gasem, "Multiphase analysis for high-pressure adsorption of $\mathrm{CO}_{2}$ /water mixtures on wet coals," Energ. Fuel 2012, 26(6): 3470-3480.
[20] S. A. Mohammad, A. Arumugam, R. L. Robinson, and K. A. M. Gasem, "High-pressure adsorption of pure gases on coals and activated carbon: Measurements and modeling," Energ. Fuel 2012, 26(1): 536-548.

[21] P. Chareonsuppanimit, S. A. Mohammad, R. L. Robinson, and K. A. M. Gasem, "High-pressure adsorption of gases on shales: Measurements and modeling," Int. J. Coal Geol. 2012, 95: 34-46.

[22] S. X. Hao, J. Wen, X. P. Yu, and W. Chu, "Effect of the surface oxygen groups on methane adsorption on coals," Appl. Surf. Sci. 2013, 264: 433-442.

[23] Y. Y. Feng, C. F. Jiang, D. J. Liu, and W. Chu, "Experimental investigations on microstructure and adsorption property of heat-treated coal chars," J. Anal. Appl. Pyrol. 2013, in press.

[24] H. J. Kim, Y. Shi, J. He, H. H. Lee, and C. H. Lee, "Adsorption characteristics of $\mathrm{CO}_{2}$ and $\mathrm{CH}_{4}$ on dry and wet coal from subcritical to supercritical conditions," Chem. Eng. J. 2011, 171(1): 45-53.

[25] Z. J. Pan, L. D. Connell, "Modelling of anisotropic coal swelling and its impact on permeability behaviour for primary and enhanced coalbed methane recovery," Int. J. Coal Geol. 2011, 85(3-4): 257-267.

[26] M. J. Lwin, "The effect of different gases on the ultrasonic response of coal," Geophysics 2011, 76(5): E155-E163.

[27] E. Battistutta, M. Lutynski, H. Bruining, K. H. Wolf, and S. Rudolph, "Adequacy of equation of state models for determination of adsorption of gas mixtures in a manometric set up," Int. J. Coal Geol. 2012, 89(1): 114-122 